\title{
Changes in the oxygen transport system of erythrocytes in testing the general endurance of students
}

\author{
Neporadna N.I. ${ }^{\mathrm{ABCD}}$, Popel' S.L. ${ }^{\mathrm{BCDE}}$ \\ Vasyl Stefanyk Precarpathian National University, Ukraine
}

Authors' Contribution: A - Study design; B - Data collection; C - Statistical analysis; D - Manuscript Preparation; E - Funds Collection.

\begin{abstract}
Purpose: $\quad$ to reveal morpho-functional changes in erythrocytes in students with different levels of general endurance. Material: It was examined 80 students (17-19 years old). The students performed a 12-min shuttle run (20m endurance shuttle-run - bleep test). The ventilation function of the lungs was estimated according to the forced exhalation data. The gas composition of the blood was determined by the gas analyzer OPTI CCA-TS.

Results: It was determined that in students with lower than average and low levels of general endurance, the increase of lungs ventilation is stipulated by the increase in the frequency of respiration. This leads to rapid tiredness of the respiratory muscles, reduces ventilation of the lungs and gas exchange. Low levels of blood oxygenation, intensity of oxidative phosphorylation and ATP resynthesis lead to the appearance of atypical forms of erythrocytes. It is established that at the low level of cardiorespiratory endurance there is an increase in the concentration of acidic metabolism products in arterial blood and reduce in its alkaline reserves.

Conclusions: Students with below average and low levels of physical fitness are characterized by: increased respiratory rate, reduced ventilation of the lungs and gas exchange. This leads to the formation of a hypoxic condition in the peripheral blood: a reduce of $\mathrm{pO}_{2}, \mathrm{pCO}_{2}$ level and the appearance of metabolic acidosis symptoms. For students with below average and low level of physical fitness hypoxic condition leads to violation of bioenergetic processes in peripheral blood erythrocytes, reduction of ATP product, increase in the content of intra-erythrocytic 2,3-BPG.

Keywords: $\quad$ students, haemoglobin, erythrocytes, hypoxia, gas exchange.
\end{abstract}

\section{Introduction}

Hypoxia is a widespread phenomenon which appears in violation of the cardiorespiratory system functions and the transport function of the blood. Hypoxia appears in physiological conditions with submaximal and maximum aerobic physical loads $[1,2]$. The increase in oxygen deficit appears in the process of performing such physical activity. This significantly reduces the intensity of oxidative phosphorylation. As a result, there is accumulation of lactic acid in the muscle tissue and in the blood and reduce of energy formation $[3,4]$.

It is known that all life processes require energy. Therefore, reduction of adenosine triphosphate (ATP) level is considered one of the main symptoms of hypoxia [3]. The intensity of oxidative phosphorylation during physical activity is reduced by $15-20 \%$ in people with a low functional reserve of the cardiorespiratory system [5]. It negatively affects the morpho-functional condition of the organism.

The study of Kuzmin et al. [6] and Ocak [7] point to low reserve capabilities of the cardiorespiratory system of modern students. It can be the reason of the negative changes in red blood cells in aerobic physical loads [8].

Other studies determine:

- The obtained results indicated that hyperoxia causes deep changes both in the composition and character of bilayer lipids of erythrocyte membranes, which affects the functional characteristics of erythrocytes, primarily the oxygen-transport properties of erythrocyte haemoglobin [9];

(c) Neporadna N.I., PopelT S.L., 2019

doi:10.15561/18189172.2019.0104
- The obtained results showed that the lipid phase plays an important role in the functioning of erythrocytes in health as well as in event of development of ischemic heart disease and other pathological processes that accompany hypoxia [10];

- The results of the study show that when the maximum physical load is performed, the microrelief is significantly enriched and the peripheral blood erythrocytes are deformed, which indicates the low stability of their membranes to the effect of various stress factors at a low level of somatic health of the students [11];

- $\quad$ RBC (red blood cell) deformability is influenced by age and endurance rate of the sport which suggests that the RBC system may adapt to changing conditions such as adolescence with the onset effects of sex hormones or physical exercise [12];

- Considering the variety of individual physiological processes in the oxygen transport system activity influenced by endurance training we studied the effective mechanisms of elements of adaptation in ski racers at rest. The obtained data suggested that wave characteristics (amplitude and frequency) of pulsatile arterial and venous blood flow (pressure) were essential for the circulation system functioning and for the high sport performance [13];

- Comparison of main stages of training and competitive conditioning in exercise tolerance revealed that activity of metabolic processes in hurdlers depended on the volume of specific muscle work in the zone of anaerobic-alactic energy supply [14];

- Changes in the TC (training camp) conditions 
result in redistribution of generalized reactions of interchangeability of the functional stability and metabolic state, mutual substitution of regulating function systems, and oscillatory changes in the specific and functional system in the integrative activity of in the middle-distance runners and steeplechasers [15];

- The study provided information on the importance of indexes reflecting a correlation of various biochemical indicators to estimate the sufficiency of training loads. [16].

Thus, there is clearly a need for more profound studies concerning the rapid tiredness of the respiratory muscles of young people, the presence of a low level of cardiorespiratory endurance during exercise on endurance.

The aim of the work is to reveal the morpho-functional changes in erythrocytes in students with different levels of general endurance.

\section{Material and methods}

Participants

The study involved 80 students (17-19 years old). Students were asked to complete a 12-min shuttle run (Eurofit test). All students were divided into groups: the first group (DG-1) - students with a higher average level of general endurance $(n=20)$; the second group (DG-2) - students with average level of general endurance $(\mathrm{n}=$ 20); the third group (DG-3) - students with below average level of general endurance $(n=20)$; the fourth group (DG4) - students with a low level of general endurance (n $=20$ ). The intergroup comparison was performed for the analysis of experimental data.

Design of research.

The ventilation function of the lungs was estimated according to the flow-volume curve of the forced exhalation. The SpiroCom + was applied (Kharkov, Ukraine). The gas composition of the blood was estimated by a gas analyzer PTI CCA-TS (Ciba Corning, Germany).
Erythrocyte medications were prepared according to generally accepted rules [17]. Erythrocyte medications were examined in the electron microscope "JEOL25A-T3225" (Japan). The percentage of different types of erythrocytes was determined by "Biovision-4.01" software (USA).

The content of 2,3-bisphosphoglycerate (2,3-BPG) and adenosine triphosphoric acid (ATP) in erythrocytes was determined by method of Kim et al. and [18]. All laboratory tests were performed before and after 12-min shuttle run. The research was conducted at the Department of Laboratory Diagnostics of the Central Clinical Hospital (№ 1, Ivano-Frankivsk, Ukraine). Students gave written consent for participation in the experiment. It was considered the requirements of the Helsinki Declaration (2008).

\section{Statistical analysis.}

The obtained data was processed by methods of nonparametric statistics applying the Mann-Whitney test. Computer processing of data was performed applying the statistical package Stat.Soft.Inc; Tulsa, OK, USA; Statistica 6. Selective parameters and text have the following meaning $\mathrm{M}$ - sample mean, $\mathrm{m}$ - standard error of the mean. Statistical changes were considered significant when the obtained significance level was determined at $\mathrm{p}<0,05-0,001$.

\section{Results}

Indicators of external breathing in students are presented in Table 1.

Students of DG-3 and DG-4 have the radical reduce of indicators $\mathrm{FEV}_{1}, \mathrm{MEF}_{25} ; \mathrm{MEF}_{50} ; \mathrm{MEF}_{75}$

At the same time, students of DG-1 have higher level of partial pressure of $\mathrm{CO}_{2}\left(\mathrm{pCO}_{2}\right)$ than students of DG-3. The alkaline surplus (BE) in students of DG-1 is lower ( $p$ $<0,05)$.

After testing, the frequency of breathing in students of DG-4 significantly increases. At the same time, it is

Table 1. Indicators of ventilation lung function in students after a 12-min shuttle run, depending on the level of cardiorespiratory endurance (in $\%$ of the proper value, $n=80$ )

\begin{tabular}{|c|c|c|c|c|c|c|}
\hline \multirow[t]{2}{*}{ Indicators } & \multicolumn{4}{|c|}{$\begin{array}{l}\text { The group of students by the level of cardiorespiratory } \\
\text { endurance }\end{array}$} & \multirow[t]{2}{*}{$\mathbf{p}$} & \multirow{2}{*}{$p_{1}$} \\
\hline & DG-1 & DG-2 & DG-3 & DG-4 & & \\
\hline VC & $112.3 \pm 1.52$ & $109.4 \pm 1.52$ & $95.9 \pm 1.25$ & $88.4 \pm 1.62$ & $<0.01$ & $<0.01$ \\
\hline FVC & $107.9 \pm 0.5$ & $98.6 \pm 0.5$ & $83.5 \pm 1.33$ & $87.6 \pm 1.78$ & $<0.05$ & $<0.01$ \\
\hline $\mathrm{FEV}_{1}$ & $94.2 \pm 0.25$ & $89.5 \pm 0.25$ & $66.3 \pm 1.05$ & $62.8 \pm 1.44$ & $<0.01$ & $>0.05$ \\
\hline $\mathrm{FEV}_{1} / \mathrm{VC}$ Tiffeneau index & $93.9 \pm 0.25$ & $83.2 \pm 0.25$ & $74.2 \pm 1.22$ & $66.7 \pm 1.53$ & $>0.001$ & $>0.05$ \\
\hline $\mathrm{MEF}_{25}$ & $92.1 \pm 3.31$ & $86.2 \pm 4.44$ & $39.9 \pm 1.15$ & $28.3 \pm 1.07$ & $>0.001$ & $<0.01$ \\
\hline $\mathrm{MEF}_{50}$ & $85.6 \pm 0.72$ & $80.7 \pm 0.53$ & $31.5 \pm 1.01$ & $29.1 \pm 1.23$ & $<0.001$ & $>0.05$ \\
\hline $\mathrm{MEF}_{75}$ & $83.9 \pm 0.57$ & $80.5 \pm 0.61$ & $38.8 \pm 1.14$ & $32.7 \pm 1.51$ & $<0.001$ & $>0.05$ \\
\hline
\end{tabular}

Notes: 1 . Corresponding units: VC is the vital capacity; FVC - forced vital capacity; $F_{E V}$ - forced expiratory volume in 1 sec; $\mathrm{MEF}_{25}$ - forced expiratory flow at $25 \% \mathrm{FVC} \mathrm{MEF}_{50}$ - forced expiratory flow at $50 \% \mathrm{FVC}$; $\mathrm{MEF}_{75}$ - forced expiratory flow at $75 \%$ FVC.

2. The level of significance between differences of DG-1 and DG-3 (p) and DG-1 and DG-4 ( $\left.p_{1}\right)$. 
revealed the reduce of $\mathrm{AB}$ indicator (true values of bicarbonate $-\mathrm{HCO}_{3}$-act), the standard values of $\mathrm{HCO}_{3}$-std bicarbonates and the change of $\mathrm{pH}$ in the acid environment. Partial pressure of $\mathrm{CO}_{2}$ and oxygen saturation $\left(\mathrm{SO}_{2}\right.$ sat) in students of DG-4 reduce, and basic buffer capacity increases.

Partial pressure of oxygen $\left(\mathrm{pO}_{2}\right)$ in venous blood of DG-3 and DG-4 students after testing is reduced to a greater extent than in students of DG-1 and DG-2. It is observed the reduce in the total amount of haemoglobin against the background of a radical reduce of $\mathrm{pO}_{2}$ in peripheral blood of students with a low level of cardiorespiratory endurance. Therefore, in the venous blood of DG-3, DG-4 students observe the increase of 2,3-BPG content.

The morpho-functional changes of red blood cells of peripheral blood appear against the background (Fig. 1). The students of DG-3, DG-4 have reduce of the content of discocysts. However, the number of echinocytes, leptocytes and degenerative forms of erythrocytes has probably increased $(\mathrm{p}<0,05)$.

In students of DG-3, DG-4 after physical activity increase the level of lactate in peripheral blood in 2,3 times (in comparison with students of DG-1 and DG-2). Students of DG-3, DG-4 have activate synthesis of 2,3BPG. In students of DG-4 this leads to reduce in the content of ATP in erythrocytes of peripheral blood in 10,5 $\pm 1,03 \%$

\section{Discussion}

It is determined that in a low level of cardiorespiratory endurance there is an increase in the concentration of acidic metabolism products in arterial blood and its reduce in alkaline reserves.

At the same time, the level of $\mathrm{pCO}_{2}$ reduces at an average in $4,0 \pm 0,12 \%$, and $\mathrm{BE}$ index increases in $28,5 \pm$ $1,07 \%$. According to Ocak data [7], this fact indicates the formation of compensated respiratory acidosis.

The novelty of our data is to determine a simultaneous increase in the respiratory rate among students of DG-4 in $25,0 \pm 1,93 \%(\mathrm{p}<0,05)$. At the same time there is an increase in the amount of acidic products in the blood. This is observed against the background of reducing the indicators of the true value of $\mathrm{HCO}_{3}$-act bicarbonate (in $8,9 \pm 0,87 \%$ ) and the standard values of $\mathrm{HCO}_{3}$-std bicarbonates (in 6,12 $\pm 0,54 \%$ ). These figures are not accidental. It is known that the change in the acid-base balance in the blood of DG-4 students leads to a shift of $\mathrm{pH}$ toward the acidic reaction. This is reflected by expressed symptoms of metabolic acidosis and hypoxia.

We for the first time discovered that at lower levels of cardiorespiratory endurance (students of DG-3 and DG-4) partial pressure of $\mathrm{CO}_{2}$ reduces, and basic buffer capacity increases. There is reduce in $\mathrm{HCO}_{3}$-act $(\mathrm{AB})$ and saturation with oxygen $\left(\mathrm{CO}_{2}\right.$ sat). Therefore, the condition of the expressed respiratory acidosis is observed in the blood of these students. Lactate acidosis is normally compensated by a carbonate buffer system and respiratory alkalosis [8].

According to Abdelha at al. [5], the same pattern is observed in tissue fluid. According to our data, it is stipulated by expressed venous hypoxia.

We have determined that against the background of a radical reduce of $\mathrm{pO}_{2}$ in the peripheral blood of DG-3 and DG-4 students there is an increase of hypoxemia in the arterial and venous blood. At the same time, the amount of oxygen reduces in 13,7 $\pm 1,4 \mathrm{~g} / 100 \mathrm{ml}$, and the saturation of haemoglobin with oxygen reduces in $14,7 \pm 1,01 \%$ (in comparison with DG-1).

The increase in the figure of actual alkaline surplus in $24,7 \%$ (in students of DG-4) indicates the hypoxic state symptoms of tissue structures. According to other authors [3], it is observed in many organs. We have found that morpho-functional changes are expressed in erythrocytes of peripheral blood (in the first place). It is known that their structural reconstruction is an integral cellular index, which indicates the development of membranopathy [8].

In reduce of the basic fraction of haemoglobin $\mathrm{HbA}$ and in increase of the minor component of $\mathrm{HbA}_{2}$, there are conformational changes in haemoglobin. This leads to premature destruction of red blood cells. It also leads to a decrease in the processes responsible for the transport of oxygen to tissues [5]. At the same time, if the students of DG-4 have increase of the thermolabel fractions content of haemoglobin, its conformational ability should radically change, which contributed to the violation of the connection of haema with globin [2]. As a result, the phenomenon is the oxidation of the iron atom before the formation of methaemoglobin [4]. It also changes the saturation of blood with oxygen. According to Karaseva $\&$ Metelitza data [19], this is due to a interrelation change of the haemoglobin with 2,3-BPG.

According to other authors [3], such changes are the limiting factor for the synthesis of ATP. This allows to explain the radical reduce in the content of ATP in students of DG-4 in erythrocytes of venous and arterial blood.

Thus, the results of our study confirm the data of scientific literature $[5,6,20]$. We could confirm that the expressed hypoxemia in students of DG-3 and DG-4 after the maximum physical activity, provoke respiratory acidosis, suppresses the energy exchange.

It can be confirmed that the limiting factor in the energy supply of peripheral blood erythrocytes is the synthesis of ATP. This is stipulated by the low difference of this marker between arteries and veins. This causes direct pathological changes in erythrocytes of peripheral blood.

Many studies [2, 4] determined that the majority of people have no significant changes in the number of reticulocytes (even at maximum physical activity). In our opinion, the reason of the anemic states in prolonged physical activity is pathological changes of peripheral blood erythrocytes.

We also defined that in the hypoxic state (after 12min shuttle run) in the students of DG-4 increase the destructive changes in peripheral blood erythrocytes. At the same time, a lot of degenerative forms appear. Simultaneously the energy processes violate: the content of ATP reduces and the content of 2,3-BPG increases. 


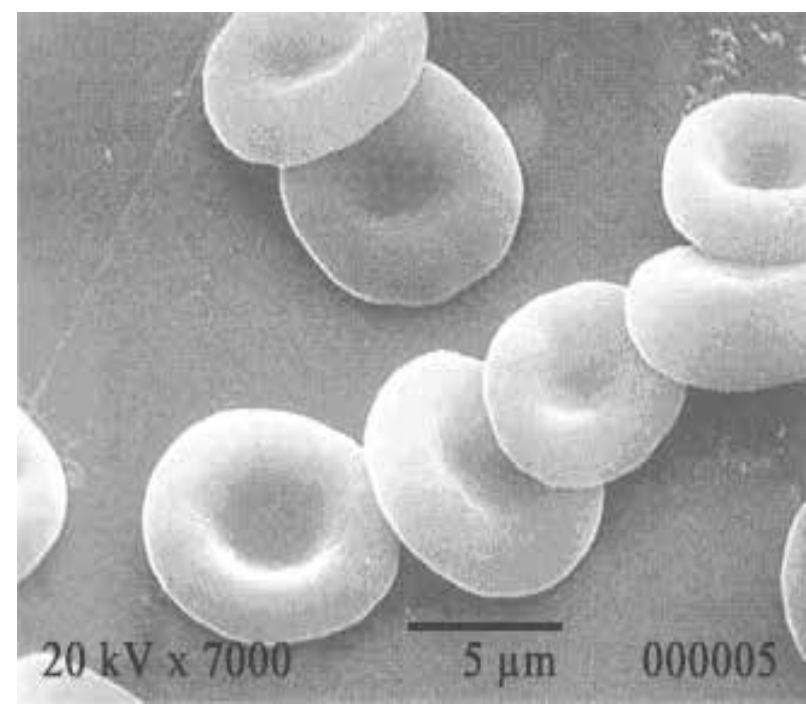

a

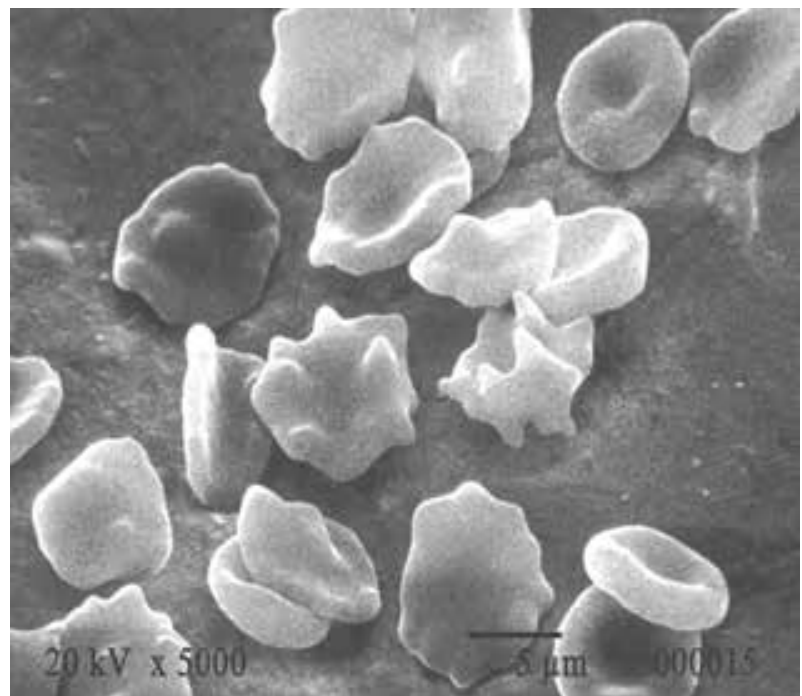

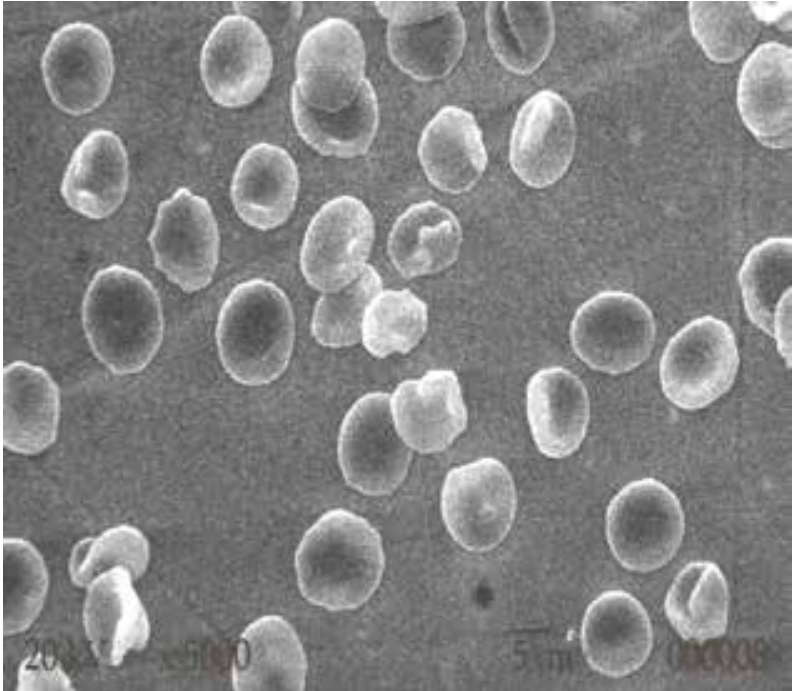

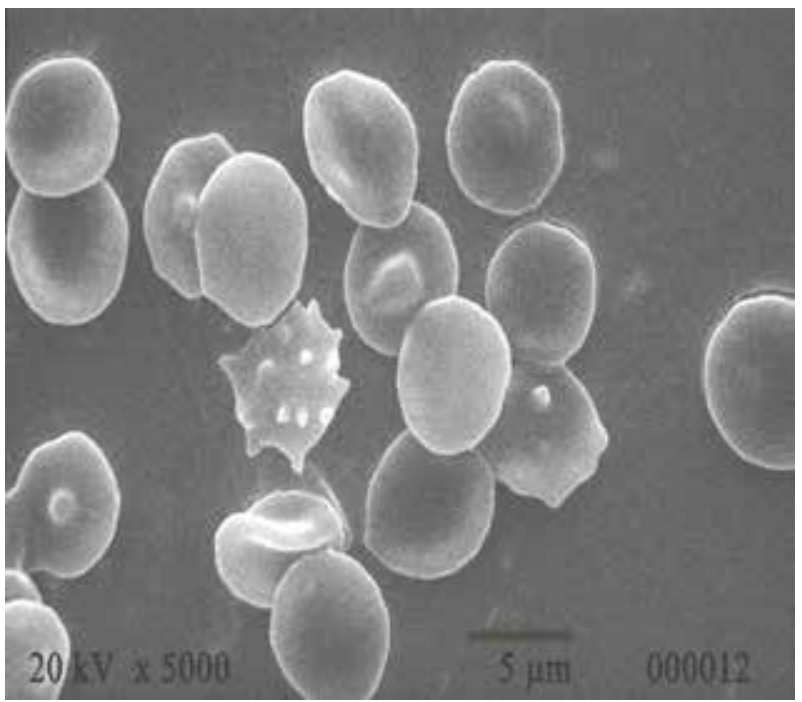

d

Fig. 1. Conformal changes in red blood cells of peripheral blood, depending on the level of physical fitness of students in performing the shuttle run test (12-min run in $20 \mathrm{~m}$ ): $a$ - above the average, $b$ - average, $c$ - lower than average, $\mathrm{d}$-low level of physical fitness. Method: scanning electron microscopy.

According to the other authors [8, 21, 22], it is consequently created multi-directional forces, which lead to deformation of the membrane. At the same time, red blood cells themselves may have extensive and deep cavities. For the first time we discovered that this is a morphological substrate for the appearance of various inverse and irreversible forms of peripheral blood red blood cells.

Particular attention should be paid to the fact that the students of DG-4 in reducing stages of the $20 \mathrm{~m}$ distances have hypoxia in the arterial $(40,4 \%, \mathrm{p}<0,05)$ and venous (in $41,4 \%, p<0,05$ ) blood. The similar processes are also developing in the students of DG-3 (but to a lesser extent).

\section{Conclusions}

1. Students with below average and low levels of physical fitness during the test of cardiorespiratory endurance are characterized by: increased respiratory rate, reduced ventilation of the lungs and gas exchange. This leads to the formation of a hypoxic state in the peripheral blood: reduce in the level of $\mathrm{pO}_{2}, \mathrm{pCO}_{2}$ and the appearance of metabolic acidosis symptoms.

2. Students with below average and low level of physical fitness have hypoxic state which leads to: violation of bioenergetic processes in peripheral blood erythrocytes, reduction of ATP product, increase in the content of intra-erythrocytic 2,3-BPG.

3. Increase of hypoxemia in peripheral blood in students with lower average and low level of physical fitness destructively affects membrane of erythrocytes. This reduces the content of discocysts and increases the number of echinocytes, leptocytes and degenerative forms of peripheral blood erythrocytes.

\section{Conflict of interest}

The authors declare that there is no conflict of interests. 


\section{References}

1. Jensen FB. The dual roles of red blood cells in tissue oxygen delivery: oxygen carriers and regulators of local blood flow. J Experimental Biology. 2009;212(21): 3387- 3393. https://doi.org/10.1242/jeb.023697

2. Mohanty JG, Nagababu E, Rifkind JM. Red blood cell oxidative stress impairs oxygen delivery and induces red blood cell aging. Frontiers in Physiology. 2014;5: 1- 5. https://doi.org/10.3389/fphys.2014.00084

3. González-AlonsoJ.ATPasamediatoroferythrocyte-dependent regulation of skeletal muscle blood flow and oxygen delivery in humans. Journal of Physiology. 2012;590(20): 5001-5013. https://doi.org/10.1113/jphysiol.2012.235002

4. Mairbäurl H. Red blood cells in sports: effects of exercise and training on oxygen supply by red blood cells. Frontiers in Physiology. 2013;4: 34- 36. https://doi.org/10.3389/fphys.2013.00332

5. Abdelha MAK, Abdelmotta S. Biochemical Changes of Hemoglobin and Osmotic Fragility of Red Blood Cells. Pakistan Journal of Biological Sciences. 2010;13(2): 73- 77. https://doi.org/10.3923/pjbs.2010.73.77

6. Kuzmin O, Melnyk O, Zhuk L. Formation of diagnostics indicator base of the university scientific activity system. Technology audit and production reserves. 2017;4(39): 9- 15. https://doi.org/10.15587/2312-8372.2018.124396

7. Ocak Y. The Four-Year an Investigation of Physical and Physiological Features of Students in a Physical Education and Sports Department. Eurasian $J$ Educational Res. 2016;16(65): 1- 35. https://doi.org/10.14689/ejer.2016.65.13

8. Popel' SL, Mitckan BM, Lapkovskiy EI. Mechanism of changing adaptation potential and morpho-biochemical parameters of erythrocytes in students with different mode of day after physical load. Regulatory Mechanisms in Biosystems. 2017;8(2), 124-134.

9. Revin VV, Gromova NV, Revina ES, Grunyushkin IP, Tychkov AY, Samonova AY, et al. The effect of experimental hyperoxia on erythrocytes' oxygen-transport function. Biotechnology \& Biotechnological Equipment. 2018;8:1-15. https://doi.org/10.1080/13102818.2017.1414633

10.Revin V, Grunyushkin I, Gromova N, Revina E, Abdulvwahid ASA, Solomadin I, et al. Effect of hypoxia on the composition and state of lipids and oxygen-transport properties of erythrocyte haemoglobin. Biotechnology \& Biotechnological Equipment. 2017;31(1):128-37. https://doi.org/10.1080/13102818.2016.1261637

11.Gavrilova NV, Yatciv YN, Lapkovskyi EI, Popel SL, Synitsa AV, Mochernyuk VB. Morphometric changes of buccal epitheliocytes and erythrocytes in students with various level of somatic health and general physical hardiness. World of Medicine and Biology. 2018(2):24-29. https://doi.org/10.26724/2079-8334-2018-2-64-24-29
12.Tomschi F, Bloch W, Grau M. Impact of Type of Sport, Gender and Age on Red Blood Cell Deformability of Elite Athletes. International Journal of Sports Medicine. 2018;39(1):12-20. https://doi.org/10.1055/s-0043-119879

13.Bakhareva A, Isaev A. Mechanisms for effective adaptation of oxygen transport system in accomplished ski racers. Gazzetta Medica Italiana Archivio Per Le Scienze Mediche. 2018;177(3):9-15. https://doi.org/10.23736/s0393-3660.17.03715-9

14.Semchenko AA, Nenasheva AV. Tendency of changes in exercise tolerance in hurdlers at different stages of training and competitive conditioning. Human Sport Medicine. 2017;17(2):89-93. https://doi.org/10.14529/hsm170209

15.Isaev AP, Romanov YN, Erlikh VV, Nenasheva AV. Integrative reactivity, resistance and tolerance of the athlete's body on the middle altitude. Minerva Ortopedica E Traumatologica. 2018;69(3):90-101. https://doi.org/10.23736/s0394-3410.18.03878-x

16. Volodchenko OA, Podrigalo LV, Iermakov SS, Żychowska MT, Jagiełło W. The Usefulness of Performing Biochemical Tests in the Saliva of Kickboxing Athletes in the Dynamic of Training. BioMed Research International. 2019 Jan 10;2019:1-7. https://doi.org/10.1155/2019/2014347

17.Hoppert M. Microscopic Techniques in Biotechnology: HOPPERT:MICROSC.TECHN. O-BK [Internet]. Weinheim, FRG: Wiley-VCH Verlag $\mathrm{GmbH} \&$ Co. KGaA; 2003 [cited 2019 Jan 13]. Available from: https://doi.org/10.1002/3527602615

18.Kim H, Kosinski P, Kung Ch, Dang L, Chen Y, Yang H, et al. A fit-for-purpose LC-MS/MS method for the simultaneous quantitation of ATP and 2,3-DPG in human K 2 EDTA whole blood. Journal of Chromatography. 2017;162: 89-96. https://doi.org/10.1016/j.jchromb.2017.07.010

19.Karaseva EI, Metelitza DI. Stabilization of glucoso-6phosphate dehydrogenase by its substrate and cofactor in an ultrasonic field.JBioorganic Chemistry. 2006;32(5): 436-443. https://doi.org/10.1134/S1068162006050062

20.Mikhaylova LA. Central hemodynamics indices in senior pupils with increased educational and motive loading. Siberian Medical Review. 2013;3: 55-58. https://doi.org/10.20333/25000136-2013-3-55-58

21.Ratcliffe PP, Bishop T. Signaling hypoxia by hypoxiainducible factor protein hydroxylases: a historical overview and future perspectives. Hypoxia. 2014;2: 197-212. https://doi.org/10.2147/HP.S47598

22.Stănciulescu R. Development of Basic Physical Qualities, Essential Condition for Creating a Competitive Physical Capacity. Scientific Bulletin. 2016;21(1): 54-60. https://doi.org/10.1515/bsaft-2016-0037 


\section{Information about the authors:}

Neporadna N.I.; http://orcid.org/0000-0002-2485-1972; nelyaneporadna@gmail.com; Vasyl Stefanyk Precarpathian National University; Shevchenko st. 57, Ivano-Frankivsk, 76018, Ukraine.

Popel' S.L.; (Corresponding author); http://orcid.org/0000-0001-9019-3966; popelsergij@gmail.com; Vasyl Stefanyk Precarpathian National University; Shevchenko st. 57, Ivano-Frankivsk, 76018, Ukraine.

Cite this article as:

Neporadna NI, Popel'SL. Changes in the oxygen transport system of erythrocytes in testing the general endurance of students. Pedagogics, psychology, medical-biological problems of physical training and sports, 2019;23(1):24-29.

https://doi.org/10.15561/18189172.2019.0104

The electronic version of this article is the complete one and can be found online at: https://www.sportpedagogy.org.ua/index.php/PPS/issue/archive

This is an Open Access article distributed under the terms of the Creative Commons Attribution License, which permits unrestricted use, distribution, and reproduction in any medium, provided the original work is properly cited (http://creativecommons.org/licenses/by/4.0/deed.en).

Received: 01.01.2019

Accepted: 05.02.2019; Published: 27.02.2019 